\title{
Diagnostic Tool for Transformer Fault Detection Based on Dissolved Gas Analysis
}

\author{
Sherif Ghoneim ${ }^{1,3}$, Kamel A. Shoush ${ }^{2,3}$ \\ ${ }^{1}$ Suez University, Egypt, ${ }^{2}$ Al-Azhar University, Egypt, ${ }^{3}$ Taif University, KSA.
}

\begin{abstract}
Dissolved gas analysis (DGA) is a diagnostic tool that used to detect the incipient faults of power transformers through the correlation between the content of gases dissolved in transformers oil and a particular malfunction. Transformer failures are often due to the lack of the dielectric strength of oil insulation and will lead to a negative impact on electrical power systems. Early stage detection of transformer faults can reduce considerably the cost of repairing the damaged transformers and hence maintain the stability of the system. Some classical methods that depend on gases concentration in transformers oils are used to interpret transformer faults such as Dornenburg, Rogers, Duval triangle and key gases methods. These methods in some cases did not give the same results; therefore, an expertise method is developed to assess the kind of fault based on the DGA. A software code is designed using logic functions to get the type of the faults in transformers from laboratory data DGA based. A comparison between the laboratory results and the code results will be accomplished. This comparison explains that the code is reliable to determine the transformer fault. The age of transformer is taken into account in our calculations. The results from the software code illustrate the program reliability as an early detection tool of transformer faults.
\end{abstract}

Key words: Dissolved gases analysis- transformer oil- interpretation of transformer faults.

\section{Introduction}

Insulation is an important part of a power transformer, in general, solid and liquid insulation are widely used. The cost of unplanned outages of power transformers can be reduced by the early detection of such internal faults. During the operational of a transformer, gasses may dissolve in transformer oil; these gasses arise as results of transformer faults such as arcing, corona (partial discharges), overheating of transformer oil or overheating of paper insulation (cellulose). Among the dissolved gasses the combustible gasses are the most dangerous since these gasses may cause the burning and/or explosion of the transformer. The combustible gasses commonly appear in transformer oil are $\mathrm{H}_{2}$ (Hydrogen), $\mathrm{C}_{2} \mathrm{H}_{6}$ (Ethane), $\mathrm{C}_{2} \mathrm{H}_{4}$ (Ethylene) and $\mathrm{C}_{2} \mathrm{H}_{2}$ (Acetylene) [1-8].

IEEE Standard C57.104-2008 describes the key gases, Doernenburg ratios, and Rogers Ratio method [9]. IEC Standard 60599 introduces the three basic gas ratio methods and the Duval triangle method [10]. Though these methods are easy to use, their performances require improvement. The IEC gas ratio method uses only three gas ratios. The Duval triangle is based on the relative proportions of the three gases for detecting a fault. Dissolved gases in oil-filled electrical equipment are very complex. DGA demonstrates better performance when a combination of gas ratios and relative proportions of gases are used to identify the fault [11].

Several artificial intelligence methods such as Fuzzy Logic and Artificial Neural Network (ANN) were developed as a novel technique to interpret the faults in transformer [12-15].

In this paper a suggested method combining the classic dissolved gases analysis (DGA) techniques for diagnosis of fault transformers with logic function is developed. Based on the interpretation of the classical techniques to the cause of transformer faults according to the gases concentration in oil transformer, an expertise system is suggested to give the cause of the transformer fault with the aid of logic functions that is used as in Fuzzy and Neural Network. A lot of real cases of analyzing the dissolved gases were collected and used to illustrate the validity of the proposed expertise method. The age of the transformer is taken into account in the calculations. In addition, some cases from previous literatures were used to compare their results with the proposed method's results.

\section{Classical Methods to Diagnose Transformer Faults}

Based on DGA, many interpretative methods have been introduced to diagnose the nature of the incipient deterioration that occurs in transformers.

Over the years, several techniques have been developed to facilitate the diagnoses of fault gases such as Dornenburg method [9], Roger's ratio method [16], Key gases method [9], and Duval Triangle method [7]. The interpretation of transformer faults using previous methods is based on the heuristic methods which depend on the experience of the analyst as well as it doesn't contain any mathematical formula. In order to overcome the 
drawback of the above mentioned methods, various recent techniques have been developed such as neural network and fuzzy logic to analysis incipient fault in transformers [12-14, 17].

\section{A. Key gases method}

The key gas method identities the key gas for each type of faults and uses the percent of this gas to diagnose the fault [9]. Key gases formed by degradation of oil and paper insulation are hydrogen $\left(\mathrm{H}_{2}\right)$, methane $\left(\mathrm{CH}_{4}\right)$, ethane $\left(\mathrm{C}_{2} \mathrm{H}_{6}\right)$, ethylene $\left(\mathrm{C}_{2} \mathrm{H}_{4}\right)$, acetylene $\left(\mathrm{C}_{2} \mathrm{H}_{2}\right)$, Carbon monoxide $(\mathrm{CO})$ and oxygen $\left(\mathrm{O}_{2}\right)$. Except for carbon monoxide and oxygen, all other gases are formed from the degradation of the oil itself. Carbon monoxide, carbon dioxide $\left(\mathrm{CO}_{2}\right)$, and oxygen are formed from degradation of cellulosic (paper) insulation. Gas type and amounts are determined based on the kind of fault in the transformer, the severity and energy of the event. Events range from low energy events such as partial discharge, which produces hydrogen and trace amounts of methane and ethane, to very high energy sustained arcing, capable of generating all the gases including acetylene, which requires the most energy. The key gas method interprets the incipient faults in transformer according to some significant gases to assign four typical fault types. These gases are called "key gases" [9] and are shown on Fig. 1.
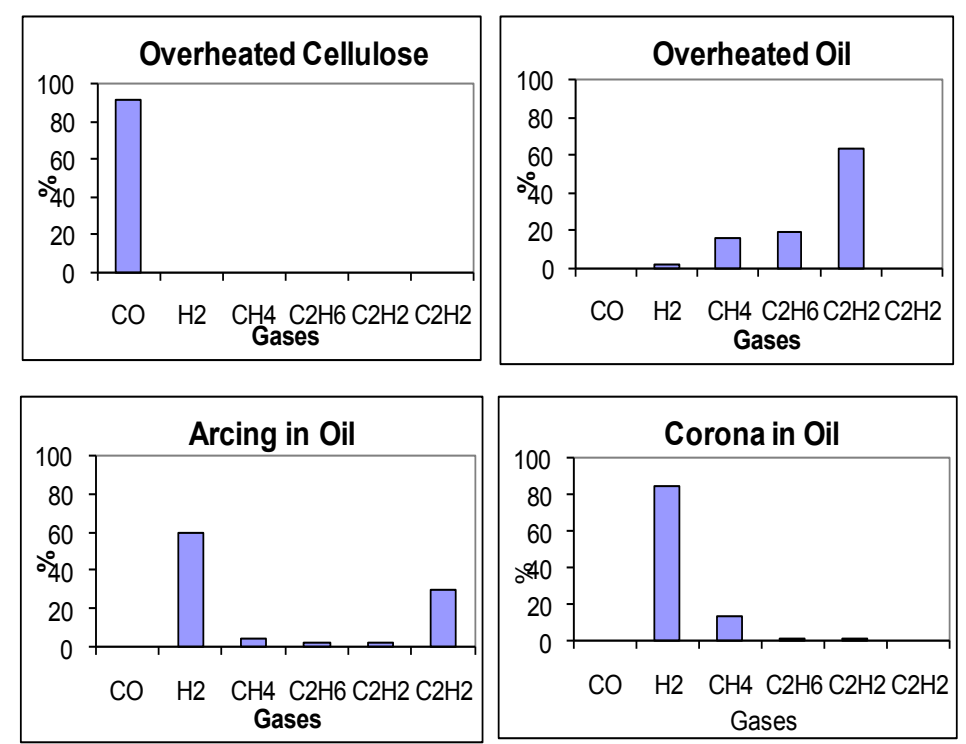

Fig. 1: Kay gas method and four typical faults.

\section{B. Dornenburg ratio method}

The Dornenburg method utilizes four calculated gas ratios to indicate a single fault type out of three general fault types. This procedure requires significant gases levels for the diagnosis to be valid. The four ratios and their diagnosis values are given on Table1[9]. Dornenburg method uses five individual gases or four-key gas ratios, which are:

$\mathrm{R}_{1}=\mathrm{CH}_{4} / \mathrm{H}_{2}$,

$\mathrm{R}_{2}=\mathrm{C}_{2} \mathrm{H}_{2} / \mathrm{C}_{2} \mathrm{H}_{4}$,

$\mathrm{R}_{3}=\mathrm{C}_{2} \mathrm{H}_{2} / \mathrm{CH}_{4}$,

$\mathrm{R}_{4}=\mathrm{C}_{2} \mathrm{H}_{6} / \mathrm{C}_{2} \mathrm{H}_{2}$.

Table 1 is used as a diagnostic ratio for Key gas method and Doernenburg method.

Table 1: Key gas ratio-Doernenburg [9]

\begin{tabular}{|c|c|c|c|c|}
\hline & \multicolumn{4}{|c|}{ Ratios for Key Gases } \\
\hline & \multicolumn{2}{|c|}{ Main Ratio } & \multicolumn{2}{c|}{ Auxiliary ratio } \\
\hline & $\mathrm{CH}_{4} / \mathrm{H}_{2}$ & $\mathrm{C}_{2} \mathrm{H}_{2} / \mathrm{C}_{2} \mathrm{H}_{4}$ & $\mathrm{C}_{2} \mathrm{H}_{6} / \mathrm{C}_{2} \mathrm{H}_{2}$ & $\mathrm{C}_{2} \mathrm{H}_{2} / \mathrm{CH}_{4}$ \\
\hline Thermal Decomposition & $>1$ & $<0.75$ & $>0.4$ & $<0.3$ \\
\hline Corona (Low intensity PD & $<0.1$ & Not significant & $>0.4$ & $<0.3$ \\
\hline Arcing (High Density PD & $<1,>0.1$ & $>0.75$ & $<0.4$ & $>0.3$ \\
\hline
\end{tabular}

\section{C. Roger's ratio method}

It is an additional tool that may be used to look at dissolved gases in transformer oil. The Rogers ratio method takes into consideration industrial experiences, laboratory tests, and further theoretical assessment. This 
method was further modified into an IEC standard $[7,10,16]$. The original Rogers ratio method uses four gas ratios which are $\mathrm{CH}_{4} / \mathrm{H}_{2}, \mathrm{C}_{2} \mathrm{H}_{6} / \mathrm{CH}_{4}, \mathrm{C}_{2} \mathrm{H}_{4} / \mathrm{C}_{2} \mathrm{H}_{6}$ and $\mathrm{C}_{2} \mathrm{H}_{2} / \mathrm{C}_{2} \mathrm{H}_{4}$ for diagnosis. The refined Rogers method uses two tables: one defined the code of the ratio, and the other defined the diagnosis rule. The ratio $\mathrm{C}_{2} \mathrm{H}_{6} / \mathrm{CH}_{4}$ indicated only a limited temperature range of decomposition, but did not assist in further fault identification. Therefore, in IEC standard 599, the further development of Roger's ratio method was deleted. Roger's ratio method and IEC 599 have gained popularity in industrial practices. However, it may give no conclusion in some cases. This is the "no decision" problem.

Table 2 shows the codes of regor's method to diagnosis the fault in transformer.

Table 2: codes for Roger's method [9]

\begin{tabular}{|c|c|c|c|c|}
\hline $\mathrm{CH}_{4} / \mathrm{H}_{2}$ & $\mathrm{C}_{2} \mathrm{H}_{2} / \mathrm{CH}_{4}$ & $\mathrm{C}_{2} \mathrm{H}_{4} / \mathrm{C}_{2} \mathrm{H}_{6}$ & $\mathrm{C}_{2} \mathrm{H}_{2} / \mathrm{C}_{2} \mathrm{H}_{4}$ & Diagnosis \\
\hline 0 & 0 & 0 & 0 & Partial discharge \\
\hline 5 & 0 & 0 & 0 & Thermal fault lower than $150^{\circ} \mathrm{C}$ \\
\hline $1 / 2$ & 0 & 0 & 0 & Thermal fault $\left(150-200^{\circ} \mathrm{C}\right)$ \\
\hline $1 / 2$ & 1 & 0 & 0 & Thermal fault $\left(200-300^{\circ} \mathrm{C}\right)$ \\
\hline 0 & 1 & 0 & 0 & Overheating in the cables \\
\hline 0 & 0 & 1 & 0 & Circulating currents in the windings \\
\hline 1 & 0 & 1 & 0 & Circulating currents in the tank and core, overheating in \\
\hline 1 & 0 & 2 & 0 & Conexions \\
\hline 0 & 0 & 0 & 1 & Arcing (high energy) \\
\hline 0 & 0 & $1 / 2$ & $1 / 2$ & Low intensity continuous discharge \\
\hline 0 & 0 & 2 & 2 & Partial discharge involving solid insulation \\
\hline 5 & 0 & 0 & $1 / 2$ & \\
\hline
\end{tabular}

\section{D. Duval triangle method}

The Duval Triangle was first developed in 1974 [7, 9] by Michel Duval using a database of about 1000 DGAs and transformer diagnoses results. Three hydrocarbon gases only $\left(\mathrm{CH}_{4}, \mathrm{C}_{2} \mathrm{H}_{4}\right.$ and $\left.\mathrm{C}_{2} \mathrm{H}_{2}\right)$ are used. These three gases are generated as a result of increasing the level of energy necessary to generate gases in transformers in service. The Duval Triangle is shown on Fig. 2 and the legend is on Table 3. In addition to the 6 zones of individual faults (PD, D1, D2, T1, T2 or T3), an intermediate zone DT has been attributed to mixtures of electrical and thermal faults in the transformer.

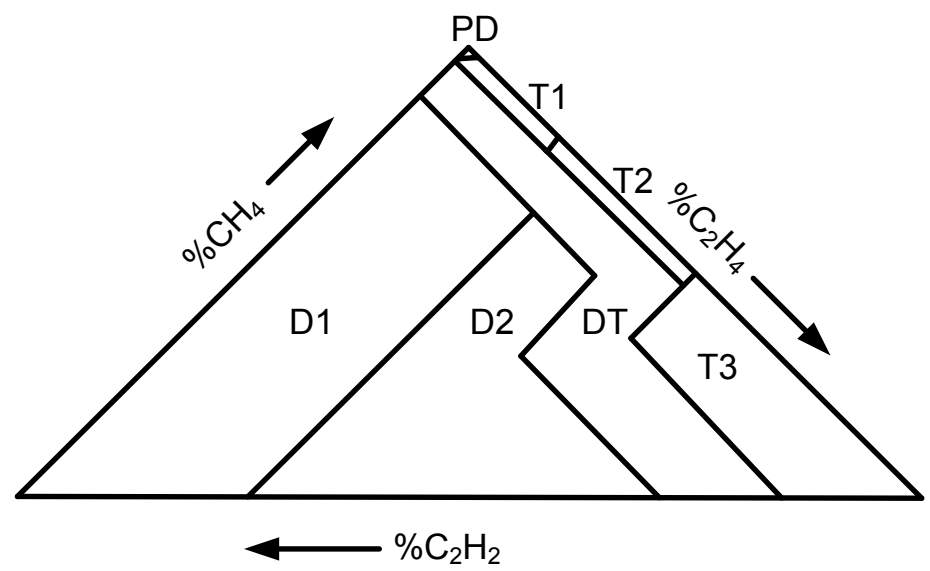

Fig.2: Duval triangle as a diagnostic tool to detect the incipient faults in transformer.

Table 3: legend of Duval triangle

\begin{tabular}{|l|}
\hline \multicolumn{1}{|c|}{ Legend } \\
\hline $\mathrm{PD}=$ Partial Discharge \\
\hline $\mathrm{T} 1=$ Thermal fault less than $300^{\circ} \mathrm{C}$ \\
\hline $\mathrm{T} 2=$ Thermal fault between $300^{\circ} \mathrm{C}$ and $700{ }^{\circ} \mathrm{C}$ \\
\hline $\mathrm{T} 3=$ Thermal fault greater than $700^{\circ} \mathrm{C}$ \\
\hline $\mathrm{D} 1=$ Low energy discharge $($ sparking) \\
\hline $\mathrm{D} 2=$ High energy Discharge (arcing) \\
\hline DT $=$ Mix of thermal and electrical fault \\
\hline
\end{tabular}




\section{Decision Tree as an Expertise Method}

When four classical methods of transformer fault diagnosis such as Key gas method, Dronenburg method, Roger's method and Duval triangle method are applied to interpret the cause of the fault in transformer, conflicts may occurred. To overcome this problem a decision fault tree is developed which contains the information between different faults types. Every fault type takes a number to help us to get the main cause of the transformer fault. This is shown in Figure 3.

A software code in excel sheet is developed using the logic function to get transformer fault from the four classical method that mentioned before; the results depend on the combustible gases that arise when fault occurs in transformer. After determining the fault type from these methods, the program decides the incipient fault type.

The procedures that used to carryout the Excel program are:

In the first, the program determines the fault type according to the classical methods; the second step is choosing a code for each fault as in decision fault tree. The third step is summing the codes for the same faults then the general fault is specified. At the end the program specifies the specific fault from the general fault using if statement and logic functions.

The age of transformer is taken into account in the calculations as the standard level of gases that mentioned in a guide for the interpretation of gas in oil analysis data (SMS-1101-05-T)[18] as a substation maintenance standard. Table.4[18] explains the recommendation guide for maximum safe evolved gas levels in oil immersed equipment.

Table 4

\begin{tabular}{|c|c|}
\hline Gas & Dissolved gas concentration (ppmV) \\
\hline $\mathrm{H}_{2}$ & $20 \mathrm{n}+50$ \\
\hline $\mathrm{CH}_{4}$ & $20 \mathrm{n}+50$ \\
\hline $\mathrm{C}_{2} \mathrm{H}_{6}$ & $20 \mathrm{n}+50$ \\
\hline $\mathrm{C}_{2} \mathrm{H}_{4}$ & $20 \mathrm{n}+50$ \\
\hline $\mathrm{C}_{2} \mathrm{H}_{2}$ & $5 \mathrm{n}+10$ \\
\hline $\mathrm{CO}$ & $25 \mathrm{n}+500$ \\
\hline $\mathrm{CO}$ & $100 \mathrm{n}+1500$ \\
\hline $\mathrm{TCG}$ & $110 \mathrm{n}+710$ \\
\hline
\end{tabular}

Where, $\mathrm{ppmV}=$ part per million, by volume, $\mathrm{n}=$ Number of years in service. Serious or danger levels are approximately 5-10 times the above values.

The number of years is effect on the Dornenburg results. This fact is shown as in Figures 4 (a and b). When the age of transformer increases, the results will give different transformer faults in case of Dornenburg method.

Figure 5 illustrates the final report and Figure 6 explains the form of the excel sheet that is used to explain the main fault in transformer.

\section{Some Cases to Specify the Fault Type in Transformers}

Some oil samples are taken from real transformers which are in operation to carry out the study. Table 5 shows the gases concentration of some real transformer and the results from the laboratory and from the proposed expertise method.

It is seen from Table 5 that, when the $\mathrm{C}_{2} \mathrm{H}_{2}$ is increased above $2 \mathrm{ppm}$, the expected fault in transformer is arcing discharge. If the dominant gases are $\mathrm{CH}_{4}$ and $\mathrm{C}_{2} \mathrm{H}_{6}$, hence the expected fault is medium thermal fault. The high thermal fault is expected when $\mathrm{CH}_{4}$ and $\mathrm{C}_{2} \mathrm{H}_{4}$ are the dominant gases.

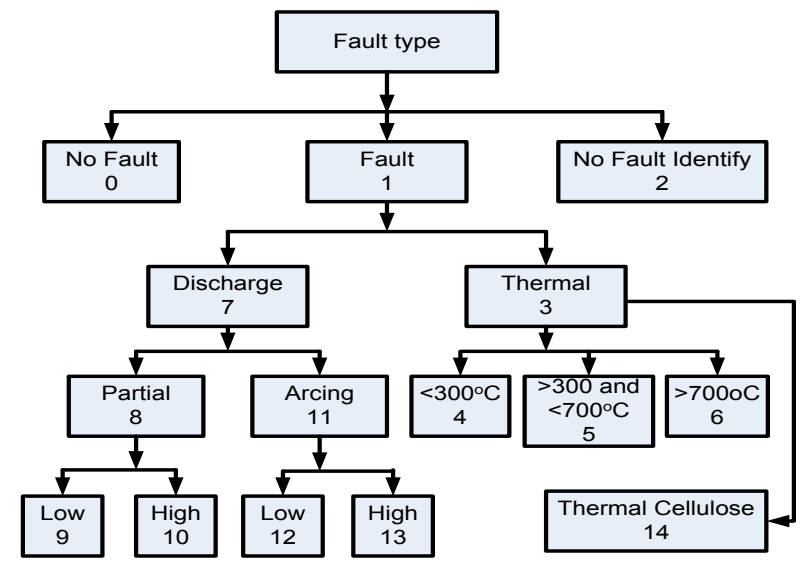

Fig. 3: Decision fault tree 


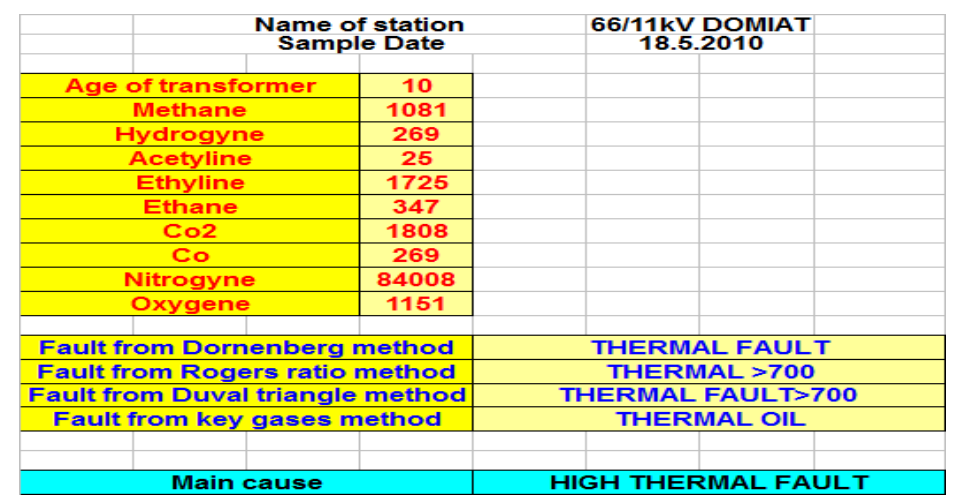

(a)

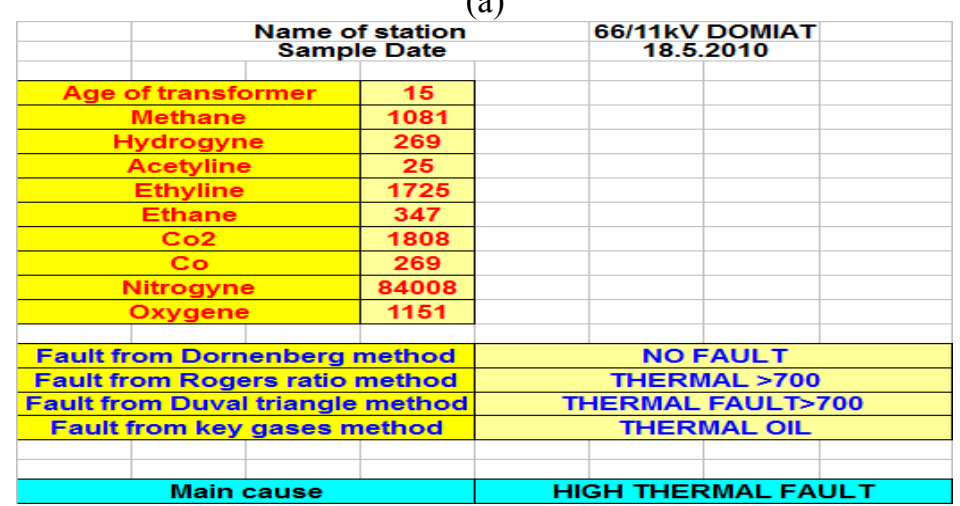

(b)

Fig. 4: The effect of age of the transformer on the result by Dornenburg method.

\begin{tabular}{|c|c|c|c|c|c|c|c|c|c|}
\hline \multicolumn{10}{|c|}{ 国 Microsoft Excel - sample1 dr sayed } \\
\hline \multicolumn{10}{|c|}{ File Eledit View Insert Format Iools Data Window Help } \\
\hline \multicolumn{10}{|c|}{ 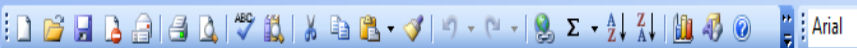 } \\
\hline \multicolumn{10}{|c|}{$f \quad f_{x}=$ codel:D37 } \\
\hline & A & $B$ & \begin{tabular}{l|l}
$c$ \\
\end{tabular} & $E$ & $\mathrm{~F}$ & G & H & 1 & $\mathrm{~J}$ \\
\hline 1 & & & \multicolumn{3}{|c|}{ Name of station } & \multicolumn{2}{|c|}{$66 / 11 \mathrm{kV}$} & & \\
\hline 2 & & & \multicolumn{3}{|c|}{ Sample Date } & \multicolumn{2}{|c|}{ 05.06.2011 } & & \\
\hline 3 & & & & & & & & & \\
\hline 4 & & \multicolumn{2}{|c|}{ Age of transformer } & 5 & & & & & \\
\hline 5 & & \multicolumn{2}{|r|}{ Methane } & 492 & & & & & \\
\hline 6 & & \multicolumn{2}{|r|}{ Hydrogyne } & 360 & & & & & \\
\hline 7 & & \multicolumn{2}{|r|}{ Acetyline } & 1 & & & & & \\
\hline 8 & & \multicolumn{2}{|r|}{ Ethyline } & 305 & & & & & \\
\hline 9 & & \multicolumn{2}{|r|}{ Ethane } & 54 & & & & & \\
\hline 10 & & \multicolumn{2}{|r|}{$\mathrm{C} 02$} & $\cdot$ & & & & & \\
\hline 11 & & \multicolumn{2}{|r|}{ Co } & 580 & & & & & \\
\hline 12 & & \multicolumn{2}{|r|}{ Nitrogyne } & $\cdot$ & & & & & \\
\hline 13 & & \multicolumn{2}{|r|}{ Oxygene } & . & & & & & \\
\hline 14 & & & & & & & & & \\
\hline 15 & & \multicolumn{3}{|c|}{ Fault from Dornenberg method } & \multicolumn{4}{|c|}{ NOFAULT } & \\
\hline 16 & & \multicolumn{3}{|c|}{ Fault from Rogers ratio method } & \multicolumn{4}{|c|}{ THERMAL >700 } & \\
\hline 17 & & \multirow{2}{*}{\multicolumn{3}{|c|}{ Fault from Duval triangle method }} & \multicolumn{4}{|c|}{1} & \\
\hline 18 & & & & & \multirow{2}{*}{\multicolumn{4}{|c|}{ THERMAL CELLULOSE }} & \\
\hline 19 & & \multicolumn{3}{|c|}{ Fault from key gases method } & & & & & \\
\hline \multicolumn{10}{|l|}{20} \\
\hline 21 & & \multicolumn{3}{|c|}{ Main cause } & \multicolumn{4}{|c|}{ HIGH THERMAL FAULT } & \\
\hline
\end{tabular}

Fig. 5: The final report 


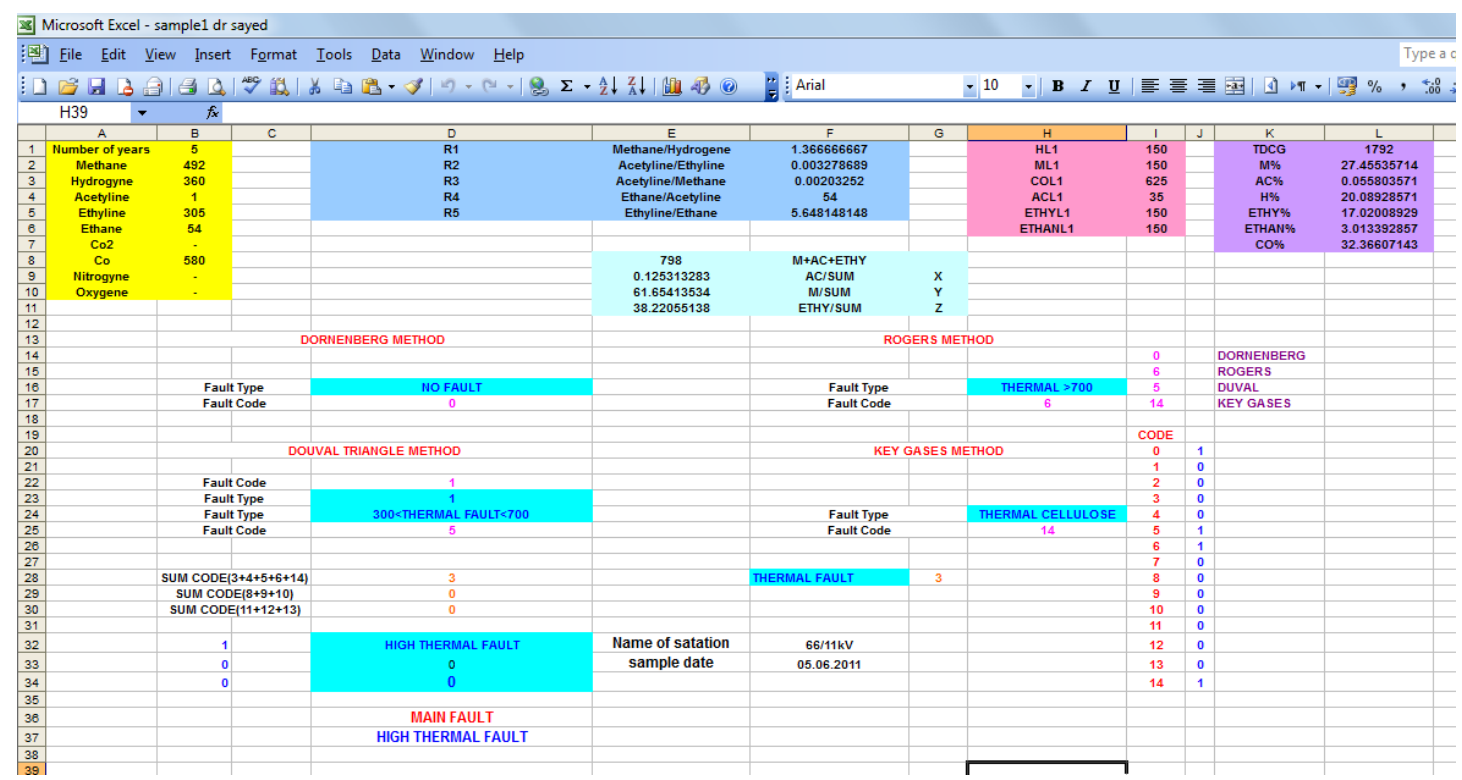

Fig. 6: The excel sheet that use to give the main cause of transform fault.

Table 5: Comparison between the laboratory results and proposed method results for some real oil transformer cases

\begin{tabular}{|c|c|c|c|c|c|c|}
\hline Transformer & $66 / 11 \mathrm{kV}$ & $66 / 11 \mathrm{kV}$ & $66 / 11 \mathrm{kV}$ & $220 / 500 \mathrm{kV}$ & $220 / 500 \mathrm{kV}$ & Talkha \\
\hline Date & 5.06 .2011 & 2.05 .2010 & 10.08 .2010 & 27.07 .2010 & 11.07 .2011 & 13.04 .2011 \\
\hline Methane $\mathrm{CH}_{4}$ & 30 & 13 & 13 & 7 & 3 & 10 \\
\hline Hydrogen $\mathrm{H}_{2}$ & 30 & 17 & 62 & 9 & 62 & 10 \\
\hline Acetylene $\mathrm{C}_{2} \mathrm{H}_{2}$ & 0.0001 & 22 & 18 & 0.0001 & 0.0001 & 0.0001 \\
\hline Ethylene $\mathrm{C}_{2} \mathrm{H}_{4}$ & 20 & 15 & 36 & 8 & 3 & 1 \\
\hline Ethane $\mathrm{C}_{2} \mathrm{H}_{6}$ & 578 & 19 & 60 & 49 & 1 & 8 \\
\hline $\begin{array}{l}\text { Carbon dioxide } \\
\mathrm{CO}_{2}\end{array}$ & 5518 & 1993 & 7238 & 3320 & 2556 & 12797 \\
\hline $\begin{array}{l}\text { Carbon mono- } \\
\text { oxide Co }\end{array}$ & 564 & 165 & 171 & 2021 & 470 & 798 \\
\hline Nitrogen $\mathrm{N}_{2}$ & 108606 & 85128 & 42812 & 68020 & 76857 & 81682 \\
\hline Oxygen $\mathrm{O}_{2}$ & 4986 & 12603 & 10120 & 12531 & 9318 & 3247 \\
\hline $\begin{array}{c}\text { LABORATORY } \\
\text { RESULTS } \\
\end{array}$ & $\begin{array}{c}\text { Thermal } \\
300-700^{\circ} \mathrm{C} \\
\end{array}$ & $\begin{array}{l}\text { Discharge of } \\
\text { high energy }\end{array}$ & $\begin{array}{l}\text { Thermal } \\
>700^{\circ} \mathrm{C} \\
\end{array}$ & $\begin{array}{l}\text { Thermal } \\
>700^{\circ} \mathrm{C}\end{array}$ & $\begin{array}{c}\text { Thermal } \\
300-700^{\circ} \mathrm{C}\end{array}$ & $\begin{array}{l}\text { Thermal } \\
<300^{\circ} \mathrm{C} \\
\end{array}$ \\
\hline $\begin{array}{l}\text { EXPERTISE } \\
\text { METHPD }\end{array}$ & $\begin{array}{c}\text { Medium } \\
\text { thermal } \\
\text { fault }\end{array}$ & $\begin{array}{l}\text { High arcing } \\
\text { discharge }\end{array}$ & $\begin{array}{c}\text { thermal } \\
\text { fault }\end{array}$ & $\begin{array}{c}\text { High } \\
\text { thermal } \\
\text { fault }\end{array}$ & $\begin{array}{l}\text { Medium } \\
\text { thermal fault }\end{array}$ & $\begin{array}{l}\text { Low } \\
\text { thermal } \\
\text { fault }\end{array}$ \\
\hline
\end{tabular}

\section{Validation of the Proposed Technique}

As in Table 6, the comparison between the results from the software code based on expertise method and the results from other methods in literatures is illustrated.

Table 6 explains the reliability and validation of the proposed expertise method for detecting the inception faults in transformer based on DGA.

\section{Conclusions}

The results from different cases under study reveal that the proposed technique is reliable to use as a diagnostic tools to detect the fault in transformer in its early stage. The conclusions from the real cases explain that the nature of the insulating materials involved in the fault and the nature of the fault itself affect on distribution of dissolved gases. Based on The results from the software code and the lab results, the software code is reliable to produce the transformer fault based on the gas concentrations.

\section{References}

[1]. Suwarno, "Dissolved Gas Analysis of Transformer Oils: Effects of Electric Arc", Proceedings of the 6th WSEAS International Conference on Power Systems, Lisbon, Portugal, September 22-24, 2006. 
[2]. H. Borsi, K. Dumke, E. Gockenbach, "Relation between Faults and Generated Gases in Transformer Liquids," Proceedings of 13 International Conference on Dielectric Liquids ( ICDL '99), Nara, Japan, July 20-25, 1999.

[3]. Sayed A. Ward "Evaluating Transformer Condition Using DGA Oil Analysis", 2003 Annual Report Conference on Electrical Insulation and Dielectric Phenomena.

[4]. E. Dornenburg, and W. Strittmater, "Monitoring Oil Cooling Transformers by Gas Analysis," Brown Boveri Review, vol. 61, pp. 238-274, 1974.

[5]. IEC Publication 599, Interpretation of the Analysis of Gases in Transformers and Other Oil-Filled Electrical Equipment in Service, First Edition, 1978.

[6]. [6] R. R. Rogers, "IEEE and IEC Codes to Interpret Incipient Faults in Transformers, Using Gas in Oil Analysis," IEEE Trans. on Electrical Insulation, vol. 13, no. 5, pp. 349-354, 1978.

[7]. M. Duval, "Dissolved Gas Analysis: It Can Save Your Transformer," IEEE Electrical Insulation Magazine, vol. 5, no. 6, pp. 22-27, 1989.

[8]. ANSI/IEEE Std C57.104-1991, IEEE Guide for The Interpretation of Gases Generated in Oil-Immersed Transformers, IEEE Power Engineering Society, 1992.

[9]. IEEE Guide for the Interpretation of Gases Generated in Oil-Immersed Transformers, IEEE Standard C57.104-2008, Feb. 2009.

[10]. "Interpretation of the analysis of gases in transformers and other oil-filled electrical equipment in service," IEC Publ. 60599, Mar. 1999.

[11]. Xiaohui Li, Huaren Wu, Danning Wu" DGA Interpretation Scheme Derived From Case Study" IEEE Transactions on Power Delivery, Vol. 26, No. 2, April 2011, pp. 1292-1293.

[12]. Fábio R. Barbosa, Otacílio M. Almeida, Arthur P. S. Braga, Cícero M. Tavares, Márcio A. B. Amora, Francisco A. P., “Artificial Neural Network Application In Estimation Of Dissolved Gases In Insulating Mineral Oil From Physical-Chemical Datas For Incipient Fault Diagnosis," IEEE Trans. Power Del., vol. 6, no. 2, pp. 601-607, Apr. 1991.

[13]. CS Chang, CW Lim, Q Su, "Fuzzy-Neural Approach for Dissolved Gas Analysis of Power Transformer Incipient Faults", Australasian Universities Power Engineering Conference (AUPEC 2004) 26-29 September 2004, Brisbane, Australia.

[14]. Rahmat-Allah Hooshmand, Mahdi Banejad, "Fuzzy Logic Application in Fault Diagnosis of Transformers Using Dissolved Gases", Journal of Electrical Engineering \& Technology, Vol. 3, No. 3, pp. 293 299, 2008.

[15]. N.A. Muhamad, B.T. Phung, T.R. Blackburn, K.X Lai," Comparative Study and Analysis of DGA Methods for Transformer Mineral Oil", Journal of Electrical Engineering \& Technology, Vol. 2, No. 2, pp. 157 164, 2007.

[16]. R. R. Rogers, "IEEE and IEC Codes to Interpret Incipient Faults in Transformers, Using Gas in Oil Analysis," IEEE Trans. on Electrical Insulation, vol. 13, no. 5, pp. 349-354, 1978.

[17]. Fathiah Zakaria, Dalina Johari, Ismail Musirin, "Artificial Neural Network (ANN) Application in Dissolved Gas Analysis (DGA) Methods for the Detection of Incipient Faults in Oil-Filled Power Transformer", 2012 IEEE International Conference on Control System, Computing and Engineering, 23 - 25 Nov. 2012, Penang, Malaysia, pp. 328-332.

[18]. Substation Maintenance standard "Guide for Interpretation of Gas In Oil Analysis Data" Index Number SMS-1101-05-T.

[19]. J. BILBAO, et. al. "Expertise Method to Diagnose Transformer Conditions", WSEAS/IASME Conferences, Corfu, Greece, August 17-19, 2004.

[20]. Joseph B. DiGiorgio, "Dissolved Gas Analysis of Mineral Oil Insulating Fluids" , Northern Technology and testing,http://www.nttworldwide.com.

Table 6: Comparison between the expertise method results and results in literatures

\begin{tabular}{|c|c|c|c|c|}
\hline case & Sample 2 in [3] & Example 1 in [19] & Example 2 in [19] & Case III in [20] \\
\hline $\mathrm{H}_{2}$ & 59 & 64 & 206 & 127 \\
\hline $\mathrm{CH}_{4}$ & 93 & 19 & 42 & 24 \\
\hline $\mathrm{C}_{2} \mathrm{H}_{2}$ & 1 & 0.001 & 82 & 81 \\
\hline $\mathrm{C}_{2} \mathrm{H}_{4}$ & 6 & 82 & 16 & 32 \\
\hline $\mathrm{C}_{2} \mathrm{H}_{6}$ & 89 & 11 & 334 & 0.0001 \\
\hline $\mathrm{CO}$ & 736 & 459 & 3432 & 2024 \\
\hline $\mathrm{CO}_{2}$ & 1519 & - & Thermal \\
recomposition & High thermal fault & Arcing Discharge & $\begin{array}{c}\text { Arcing not involve } \\
\text { cellulose }\end{array}$ \\
\hline $\begin{array}{c}\text { Expertise } \\
\text { Meth. }\end{array}$ & Low thermal fault & $\begin{array}{c}\text { Thermal } \\
\text { fault }>700^{\circ} \mathrm{C}\end{array}$ & $\begin{array}{c}\text { High arcing } \\
\text { discharge }\end{array}$ & High arcing discharge \\
\hline
\end{tabular}

